\title{
A Phase I Trial of Vorinostat and Bortezomib in Children with Refractory or Recurrent Solid Tumors: A Children's Oncology Group Phase I Consortium Study (ADVL0916)
}

Jodi A. Muscal, MD ${ }^{1}$, Patrick A. Thompson, MD ${ }^{1}$, Terzah M. Horton, MD, PhD ${ }^{1}$, Ashish M. Ingle, MS ${ }^{2}$, Charlotte H. Ahern, PhD $^{3}$, Renee M. McGovern, BS ${ }^{4}$, Joel M. Reid, PhD $^{4}$, Matthew M. Ames, $\mathrm{PhD}^{4}$, Igor Espinoza-Delgado, MD ${ }^{5}$, Brenda J. Weigel, $\mathrm{MD}^{6}$, and Susan M. Blaney, MD ${ }^{1}$

${ }^{1}$ Texas Children's Cancer Center and Department of Pediatrics, Baylor College of Medicine, Houston, TX

${ }^{2}$ Children's Oncology Group, Arcadia, CA

${ }^{3}$ Dan L. Duncan Cancer Center, Baylor College of Medicine, Houston, TX

${ }^{4}$ Department of Oncology, Mayo Clinic, Rochester, MN

${ }^{5}$ Cancer Therapy Evaluation Program, Division of Cancer Treatment and Diagnosis, National Cancer Institute, Bethesda, MD

${ }^{6}$ Department of Pediatrics, Hematology-Oncology, University of Minnesota, Minneapolis, MN

\section{Abstract}

Background-A pediatric phase I trial was performed to determine the maximum tolerated dose, dose-limiting toxicities (DLTs), and pharmacokinetics (PK) of vorinostat and bortezomib, in patients with solid tumors.

Procedure-Oral vorinostat was administered on days $1-5$ and $8-12$ of a 21 day cycle (starting dose $180 \mathrm{mg} / \mathrm{m}^{2} /$ day with dose escalations to 230 and $300 \mathrm{mg} / \mathrm{m}^{2} /$ day). Bortezomib $\left(1.3 \mathrm{mg} / \mathrm{m}^{2}\right.$ i.v.) was administered on days $1,4,8$, and 11 of the same cycle. PK and correlative biology studies were performed during cycle 1 .

Results-Twenty-three eligible patients [17 male, median age 12 years (range, 1-20)] were enrolled of whom 17 were fully evaluable for toxicity. Cycle 1 DLTs that occurred in 2/6 patients at dose level 3 (vorinostat $300 \mathrm{mg} / \mathrm{m}^{2} /$ day) were grade 2 sensory neuropathy that progressed to grade $4(n=1)$ and grade 3 nausea and anorexia $(n=1)$. No objective responses were observed. There was wide interpatient variability in vorinostat PK parameters. Bortezomib disposition was best described by a three-compartment model that demonstrated rapid distribution followed by prolonged elimination. We did not observe a decrease in NF- $\mathrm{kB}$ activity or Grp78 induction after bortezomib treatment in PBMCs from solid tumor patients.

Conclusion-The recommended phase 2 dose and schedule is vorinostat $\left(230 \mathrm{mg} / \mathrm{m}^{2} /\right.$ day PO on days $1-5$ and $8-12)$ in combination with bortezomib $\left(1.3 \mathrm{mg} / \mathrm{m}^{2} /\right.$ day i.v. on days $1,4,8$, and 11 of a 21 day cycle) in children with recurrent or refractory solid tumors.

Corresponding author: Jodi Muscal, Texas Children's Cancer Center, 1102 Bates Street, Suite 1220, Houston, TX 77030. Phone: 832-824-4588. Fax: 832-825-4039. jamuscal@txch.org.

This work was presented at the 2011 American Society of Clinical Oncology Annual Meeting, June 6, 2011 and Children's Oncology Group 2011 Annual Meeting, September, 15, 2011.

CONFLICTS OF INTEREST STATEMENT: Nothing to declare. 


\section{Keywords}

vorinostat; bortezomib; phase I trial; pediatric cancer; solid tumors; Children's Oncology Group

\section{INTRODUCTION}

Bortezomib is a selective inhibitor of the ubiquitin-proteasome pathway, which is essential for the degradation of most regulatory intracellular proteins, including those involved in control of the cell cycle, transcriptional activation, apoptosis, and cell signaling (1). Inhibition of the ubiquitin-proteasome pathway affects numerous proteins, including nuclear factor- $\kappa \mathrm{B}(\mathrm{NF}-\kappa \mathrm{B})(2)$. One mechanism for bortezomib's antitumor activity may be stabilization of the NF- $\kappa$ B inhibitor, I $\kappa \mathrm{B}$. Bortezomib also induces misfolded proteins and the initiation of the unfolded protein response (UPR) in the endoplasmic reticulum (ER). With UPR activation, the molecular chaperone protein, Grp78, is recruited to facilitate clearance of misfolded proteins (3). The UPR is a series of highly specific signaling pathways that are required for cell survival in the face of ER stress (4). When evaluated in the Pediatric Preclinical Testing Program (PPTP), bortezomib showed widespread in vitro anti-tumor activity and in vivo solid tumor activity limited to rhabdomyosarcoma, Wilms tumor, osteosarcoma, and medulloblastoma (5). Dose-limiting toxicities (DLTs) of bortezomib in prior pediatric single agent trials have included thrombocytopenia, confusion, and febrile neutropenia associated with hypotension and an elevated creatinine $(6,7)$. Bortezomib is currently approved by the US Food and Drug Administration (FDA) for use in the treatment of patients with multiple myeloma and for the treatment of patients with mantle cell lymphoma who have received at least one prior therapy.

Vorinostat, a pan-histone deacetylase (HDAC) inhibitor, was approved by the FDA in 2006 and is currently approved for the treatment of cutaneous manifestations in patients with cutaneous T-cell lymphoma who have progressive, persistent, or recurrent disease on or following two systemic therapies. HDAC inhibitors are hypothesized to reactivate gene expression of critical pathways that are abnormally silenced in tumorigenesis. Treatment of multiple tumor types with HDAC inhibitors results in cell cycle arrest, induction of apoptosis, and differentiation $(8,9)$. Preclinical studies have demonstrated that HDAC inhibitors, including vorinostat, have anti-tumor activity in a variety of pediatric cancers including leukemia (10-12), neuroblastoma $(13,14)$, and central nervous system (CNS) tumors $(15,16)$. The DLTs of vorinostat administered as a single agent to children with recurrent or refractory cancer were neutropenia, thrombocytopenia, and hypokalemia (17).

There is evidence that histone acetylation and proteasome inhibition have synergistic anticancer effects, including inhibition of tumor cell proliferation (18-28). The aggresome pathway is a proteasome-dependent pathway that eliminates misfolded proteins and HDAC6 plays an essential role in aggresomal protein degradation. It has been shown that targeting the proteasome-dependent pathways with bortezomib and the aggresome pathway with HDAC inhibitors leads to a greater accumulation of polyubiquitinated proteins with a resultant increase in cell stress and apoptosis $(29,30)$.

The combination of vorinostat and bortezomib in adults with multiple myeloma $(31,32)$ and solid tumors (33) has been studied with observed DLTs of fatigue and a prolonged QT interval. The recommended phase 2 regimen in adults with solid tumors is vorinostat $400 \mathrm{mg}$ $\left(\sim 200 \mathrm{mg} / \mathrm{m}^{2}\right)$ daily for eight days every 21 days and bortezomib $1.3 \mathrm{mg} / \mathrm{m}^{2} /$ dose on days 1 , 4,8 , and $11(33)$. 
We report the results of a phase I trial of vorinostat in combination with bortezomib in children with recurrent or refractory solid tumors, including CNS tumors. The primary objectives were to determine the MTD and/or recommended Phase 2 dose of the combination, define and describe the toxicities, and characterize the pharmacokinetics of vorinostat and bortezomib. Secondary objectives included response evaluation, assessment of NF- $\kappa$ B activity, and Grp78 induction in peripheral blood mononuclear cells (PBMCs) at 4 and 24 hours after bortezomib administration.

\section{METHODS}

\section{Patient Eligibility}

Patients older than 12 months and younger than 22 years with measurable or evaluable recurrent or refractory solid tumors, including CNS tumors or lymphomas, were eligible. Histologic verification of malignancy was required except for patients with intrinsic brainstem glioma, optic pathway glioma, or pineal tumor and elevation of serum or cerebrospinal tumor markers. Other eligibility criteria included: Lansky or Karnofsky score $\geq 60$; recovery from the acute toxic effects of prior therapy; $\geq 6$ months since total body irradiation, craniospinal or hemi-pelvic radiation, and $\geq 3$ months since a stem cell transplant; adequate bone marrow function for patients with solid tumors (peripheral absolute neutrophil count $\geq 1,000 / \mu \mathrm{L}$, platelets $\geq 100,000 / \mu \mathrm{L}$ [transfusion independent], hemoglobin $\geq 8.0 \mathrm{~g} / \mathrm{dL}$; adequate renal function [age-adjusted normal serum creatinine or a glomerular filtration rate $270 \mathrm{~mL} / \mathrm{min} / 1.73 \mathrm{~m}^{2}$ ]; adequate liver function [total bilirubin $\leq$ $1.5 \times$ institutional upper limit of normal for age, ALT $\leq 110 \mathrm{U} / \mathrm{L}$ and albumin $\geq 2 \mathrm{~g} / \mathrm{dL}$; ; and adequate cardiac function [QTc $\leq 450$ milliseconds]). Patients with solid tumors with known bone marrow metastatic disease were eligible if they were not refractory to red cell or platelet transfusions but were not evaluable for hematologic toxicity. Patients were excluded if they had received valproic acid prior to enrollment; if they were receiving enzymeinducing anticonvulsants or other noncytotoxic anticancer agents; if they were pregnant or lactating, or if they had uncontrolled infections. Patients with $\geq$ grade 2 peripheral neuropathy in the previous 2 weeks were excluded. Patients with CNS malignancies receiving corticosteroids had to be on a stable or decreasing dose for $\geq 7$ days. The institutional review boards of participating institutions approved the protocol. Informed consent and assent, as appropriate, were obtained according to local institutional guidelines.

\section{Drug Administration}

Vorinostat was supplied by the Cancer Therapy Evaluation Program (CTEP) (National Cancer Institute, Bethesda, MD) as a $100 \mathrm{mg}$ gelatin capsule. A dosing nomogram was used to minimize interpatient dosing variability. For patients who could not swallow capsules or whose body surface area was $<1.25 \mathrm{~m}^{2}$, a suspension $(50 \mathrm{mg} / \mathrm{mL})$ was prepared locally by the investigational pharmacies by mixing $20 \mathrm{~mL}$ of Suspensol S (Paddock Laboratories, Minneapolis, MN) or OraPlus (Paddock Laboratories, Minneapolis, MN) with the contents of twenty $100 \mathrm{mg}$ vorinostat capsules. After shaking for three minutes to disperse, an additional $20 \mathrm{~mL}$ of OraSweet (Paddock Lab, Minneapolis, MN) was added, and the container was again shaken to disperse. Vorinostat was administered orally on days 1-5 and $8-12$, preferably with food. Bortezomib was supplied by CTEP as a lyophilized powder and reconstituted with normal saline for intravenous administration as a $3-5$ second bolus.

The starting dose of vorinostat was $180 \mathrm{mg} / \mathrm{m}^{2} /$ day (approximately $80 \%$ of the adult recommended dose of $400 \mathrm{mg}$ daily) on days 1-5 and 8-12 with dose escalations in 30\% increments to $230 \mathrm{mg} / \mathrm{m}^{2} /$ day and $300 \mathrm{mg} / \mathrm{m}^{2} /$ day. The starting dose of bortezomib was 1.3 $\mathrm{mg} / \mathrm{m}^{2} /$ day, which is the adult MTD. De-escalation of bortezomib to $1.0 \mathrm{mg} / \mathrm{m}^{2} /$ day was planned if dose-limiting toxicity was observed at the starting dose level. 


\section{Study Design}

This dose escalation study utilized a rolling six design (34). Briefly, up to six patients were enrolled concurrently at the starting dose. Enrollment to subsequent dose levels was determined by the number of enrolled patients, the number with DLT, and the number at risk for DLT.

Toxicity was graded according to the Common Terminology Criteria for Adverse Events version 3.0 (http://ctep.cancer.gov). Hematologic DLT was defined as grade 4 neutropenia for $>7$ days, grade 4 thrombocytopenia on two separate days, or requiring a platelet transfusion on two separate days, within a seven day period, or myelosuppression that caused a delay of $>14$ days between treatment cycles. Nonhematologic DLT was defined as grade 3 or 4 nonhematologic toxicity attributable to the investigational drug with the exclusion of grade 3 nausea and vomiting of fewer than three days duration, grade 3 transaminase elevation that returned to $\leq$ Grade 1 or baseline prior to the time for the next treatment cycle, grade 3 fever or infection, or grade 3 electrolyte abnormalities responsive to oral supplementation. Nonhematologic DLT included any peripheral neuropathy that resulted in a modification or discontinuation of bortezomib dose or a nonhematologic toxicity that caused a delay of $\geq 14$ days between treatment cycles. Any patient who experienced a DLT at any time during protocol therapy was evaluable for adverse effects. Patients without DLT who received at least $85 \%$ of the prescribed dose per protocol guidelines and had the appropriate toxicity monitoring studies performed were evaluable for adverse effects. The maximum tolerated dose (MTD) was the maximum dose at which fewer than one-third of patients experienced a DLT during cycle 1 of therapy.

Tumor response was reported using the Response Evaluation Criteria in Solid Tumors (RECIST) (35) or for CNS tumors, the product of bidirectional diameters, assessment of target lesions, serum markers, and evidence of new lesions.

\section{Study Evaluations}

Pretreatment evaluations included a history, physical examination, and $\mathrm{CBC}$, electrolytes, renal and liver function tests, serum protein, and albumin. CBCs were obtained twice weekly during the first cycle and weekly thereafter. History, physical examinations, and laboratory studies were obtained weekly in cycle 1 and before each subsequent cycle. Disease evaluations were obtained at baseline, at the end of cycle 1, and after every other cycle.

\section{Pharmacokinetic Studies}

Sample Collection-Blood samples $(1 \mathrm{~mL})$ for bortezomib pharmacokinetic studies were collected in consenting patients and placed in EDTA tubes before the day 8 bortezomib infusion and at 5, 15, 30 minutes, and 1, 2, 4, 6, 8, 12, 24, 48, and 72 hours after day 8 of cycle 1 . Plasma was separated by centrifugation at $2,000 \times \mathrm{g}$ for 15 minutes, transferred into a polypropylene tube, isolated and stored at $-70^{\circ} \mathrm{C}$ until analysis. Blood samples $(1.5 \mathrm{~mL})$ for vorinostat pharmacokinetics were collected in anticoagulant-free tubes before day 8 treatment and at $0.5,1,2,4,6,8,24$, and 48 hours following drug administration on day 8 of cycle 1 . Serum samples were stored at $4^{\circ} \mathrm{C}$ for $20-30$ minutes. The serum was then separated by centrifugation at $2,000 \times \mathrm{g}$ for 15 minutes at $4^{\circ} \mathrm{C}$, transferred into polypropylene tubes, and stored at $-70^{\circ} \mathrm{C}$ until analysis.

Sample Analysis-Plasma bortezomib concentrations were measured using liquid chromatography/mass spectrometry assay. The lower limit of quantitation for bortezomib in plasma was $0.1 \mathrm{ng} / \mathrm{mL}$, and the assay was linear between 0.1 and $25.0 \mathrm{ng} / \mathrm{mL}$. The inter-day accuracy was $98 \%$ with a coefficient of variation of 3.5-6.2\%. Full details are available in 
the supplementary material. The plasma concentrations of vorinostat and vorinostat metabolites, 4-anilino-4-oxybutanoic acid and vorinostat glucuronide, were determined by liquid chromatography, tandem mass spectrometry assay (36). The lower limit of quantitation was $1 \mathrm{ng} / \mathrm{mL}$ for vorinostat and its metabolites.

Serum concentration-time data for vorinostat and its metabolites were analyzed using standard noncompartmental methods with WinNonlin Professional, version 4.1 (Pharsight Corporation, Mountain View, CA). Plasma concentration-time data for bortezomib were fit to a three-compartment model using ADAPT II as previously described (7).

\section{Biologic Assays}

Determination of NF-KB activity by ELISA-PBMCs were isolated from patient whole blood using Lymphoprep solution (Axis-Shield, Oslo, Norway) before bortezomib treatment and at 4 and 24 hours following the first bortezomib dose. Mononuclear cells were processed as previously described (7). NF- $\mathrm{\kappa B}$ binding activity ( $\mathrm{ng} / \mathrm{mg}$ protein) was calculated as an average of triplicate ELISA determinations.

Immunoblot analysis-Patient peripheral PBMCs were isolated and processed and immunoblot was performed as previously described (7). Immunoblots were incubated overnight $\left(4^{\circ} \mathrm{C}\right)$ with anti-Grp78 (1:200; BD Biosciences, San Diego, CA) or $\beta$-actin (1:10,000; Sigma, St. Louis, MO) antibodies diluted in Odyssey blocking buffer (Li-Cor, Lincoln, NE). Bound primary antibodies were detected with IR-800 dye-labeled secondary antibodies (Li-Cor) and the signal was visualized on a Li-Cor Odyssey IR scanner. The intensity of the gel bands was quantified using ImageQuant software (GE Healthcare, Uppsala, Sweden).

\section{RESULTS}

Twenty-three patients were enrolled on study between January and December 2010. Six patients were not fully evaluable for toxicity: two patients did not complete cycle 1 (one was removed from study for tumor-related pleural effusion and one had an elevated ALT, unlikely related to study drug, that precluded administration of the complete course of therapy), two missed required safety studies, one received an incorrect dose of vorinostat, and one withdrew consent. Patients received a median of one cycle (range, 1 to 3 ) of therapy (Table I).

\section{Toxicity}

Table II summarizes the observed DLTs. At the third dose level (vorinostat $300 \mathrm{mg} / \mathrm{m}^{2} /$ day on days $1-5$ and $8-12$ and bortezomib $1.3 \mathrm{mg} / \mathrm{m}^{2} /$ day on days $1,4,8$, and 11 ), two patients experienced DLT, thus dose level 2 (vorinostat $230 \mathrm{mg} / \mathrm{m}^{2} / \mathrm{day}$ and bortezomib $1.3 \mathrm{mg} / \mathrm{m}^{2}$ / day) is the recommended phase 2 dose. At the third dose level, one patient experienced grade 2 sensory neuropathy during cycle 1 , after the fourth dose of bortezomib. The patient had stable disease on imaging but elected to stop protocol therapy as a result of this toxicity. The neuropathy progressed over the ensuing $2 \frac{1}{2}$ weeks to grade 4 , requiring intensive analgesia for pain and physical rehabilitation. He did not have evidence of a pre-existing neuropathy. Another patient at the third dose level experienced grade 3 nausea and anorexia lasting more than three days. The patient completed cycle 1 at the next lowest dose level before stopping protocol therapy for progressive disease. A third patient experienced grade 2 neuropathy during cycle 2 and received a reduced dose of bortezomib during cycle 3 . When the patient again experienced grade 2 neuropathy during cycle 3 , it met the criteria for dose limiting toxicity, and protocol therapy was discontinued. Additionally, there was one patient each at the second and third dose levels who experienced grade 1 neuropathy during cycle 1 . 
Table III summarizes adverse events $\geq$ grade 2 at least possibly attributable to vorinostat or bortezomib in the 17 evaluable patients.

\section{Responses}

No objective responses were observed. One patient with neuroblastoma treated at the first dose level remained on study into the fourth cycle until he withdrew consent due to nausea after bortezomib.

\section{Pharmacokinetics}

Results of day 8, cycle 1 pharmacokinetic studies in consenting patients are shown in Table IV (vorinostat) and Table V (bortezomib). There was considerable inter-patient variability in vorinostat pharmacokinetic parameters. The mean half-life of vorinostat was 4.7 hours and the mean apparent clearance was $198 \mathrm{~L} / \mathrm{m}^{2}$. Bortezomib elimination was best described by a three-compartment model.

\section{NF-kB activity following bortezomib treatment}

Because bortezomib's inhibition of NF- $\mathrm{KB}$ activity may contribute to its antitumor effects, we analyzed NF- $\kappa$ B activity before and after bortezomib treatment. As shown in Figure 1, pretreatment NF- $\mathrm{kB}$ activity levels in PBMCs were the same or increased compared to NF$\mathrm{\kappa B}$ activity levels 24 hours after bortezomib administration.

\section{Grp78 expression following bortezomib treatment}

Because bortezomib induced Grp78 mRNA and protein levels in previous studies (4), we analyzed Grp78 protein expression before and after bortezomib treatment in the PBMCs of pediatric solid tumor patients. In four of the seven samples, the protein was degraded. In the three remaining samples, there was no induction of Grp78 detected.

\section{DISCUSSION}

This study examined the toxicity and tolerable dose of vorinostat in combination with bortezomib in pediatric patients with refractory or recurrent solid tumors, including CNS tumors. Due to dose limiting neuropathy experienced by one patient and nausea and anorexia experienced by a second patient at the third dose level (vorinostat $300 \mathrm{mg} / \mathrm{m}^{2} /$ day and bortezomib $1.3 \mathrm{mg} / \mathrm{m}^{2} /$ day), the MTD was vorinostat $230 \mathrm{mg} / \mathrm{m}^{2} /$ day on days $1-5$ and $8-12$ and bortezomib $1.3 \mathrm{mg} / \mathrm{m}^{2} /$ day on days $1,4,8$, and 11 . Neuropathy following bortezomib is a known adverse event in adults (37) and mild neuropathy (grades 1 and 2) has been reported in two children who received bortezomib combined with chemotherapy (38). On this trial, two children who were treated at the third dose level experienced grade 2 neuropathy. In one child, the neuropathy occurred during cycle 2 . The patient received dosemodified bortezomib in the next cycle. When the toxicity recurred, the patient was removed from protocol therapy, and the toxicity resolved within two weeks of onset. In a second patient, the neuropathy started in cycle 2 as grade 2, and despite stopping protocol therapy, the neuropathy progressed to grade 4 . This is the first known case of severe neuropathy associated with bortezomib in a child. In general, the hematologic and non-hematologic toxicities on this study, including neuropathy, fatigue, anorexia, nausea, vomiting, and myelosuppression, were similar to prior studies of vorinostat and bortezomib $(31,32,39$ 43).

Pharmacokinetics of vorinostat (Table IV) and bortezomib (Table V) were evaluated following the day 8 dose to determine the accumulation kinetics of both drugs after multiple doses. Bortezomib pharmacokinetics were best described by a three-compartment model. We detected low plasma concentrations of bortezomib prior to the day 8 dose, suggesting 
that bortezomib accumulates when dosed every three days. Compared with a prior study of bortezomib in children, the terminal elimination half-life was significantly (10x) longer (7). The longer terminal elimination half-life is a result of sampling bias; in our study we sampled to the 72 hour timepoint whereas in the previous study, the last timepoint was 24 hours. As has previously been demonstrated after oral vorinostat administration, there was tremendous interpatient variability in vorinostat disposition (17).

NF- $\kappa$ B activity in PBMCs was detected in patients prior to and at 4 and 24 hours following the first dose of bortezomib. Since bortezomib inhibits the ubiquitin-proteasome pathway, we expected to see NF- $\mathrm{kB}$ inhibition after bortezomib treatment, similar to our previously reported results in leukemia cells where we observed a decrease in NF- $\mathrm{kB}$ in lymphoblasts in both bone marrow and peripheral blood (7). However, in approximately half of the patient samples from this trial, we observed an increase in NF- $\mathrm{BB}$ activation at 24 hours. Since the cells analyzed were PBMCs and presumably "normal" cells from patients with solid tumors, it is possible that in samples with increased NF- $\mathrm{KB}$ activation, the cells are demonstrating a chemotherapy-induced stress response. Also in PBMCs, we investigated Grp78, a marker of ER stress, and we were not able to detect Grp78 induction after bortezomib treatment compared with pre-treatment samples, suggesting that the UPR is not induced in normal PBMCs from patients with solid tumors.

In summary, 23 children with recurrent or refractory solid tumors and CNS tumors were enrolled in the phase I trial of vorinostat in combination with bortezomib, and we recommend a phase 2 dose of vorinostat $230 \mathrm{mg} / \mathrm{m}^{2} /$ dose orally on days $1-5$ and $8-12$ along with bortezomib $1.3 \mathrm{mg} / \mathrm{m}^{2} /$ dose i.v. on days $1,4,8$, and 11 of a 21 day cycle. We observed the first pediatric patient with severe neurotoxicity on a trial including bortezomib. NF- $\mathrm{kB}$ activity and Grp78 expression did not correlate with dose. Although there were no observed responses, vorinostat in combination with bortezomib was generally well-tolerated and may have a role in other patient populations, such as patients with hematological malignancies, or in combination with cytotoxic agents.

\section{Supplementary Material}

Refer to Web version on PubMed Central for supplementary material.

\section{Acknowledgments}

This study was supported by the National Cancer Institute (NCI) Phase I/Pilot Consortium U01 CA97452, the NCI Pediatric Clinical Oncology Research Training Program 5K12CA90433-09 (JAM), the Kappa Alpha Theta Research Scholar Award (JAM), and the Carousel Faculty Research Scholar Award (JAM).

\section{REFERENCES}

1. Adams J, Palombella VJ, Sausville EA, et al. Proteasome inhibitors: A novel class of potent and effective antitumor agents. Cancer Res. 1999; 59:2615-2622. [PubMed: 10363983]

2. Jackson G, Einsele H, Moreau P, et al. Bortezomib, a novel proteasome inhibitor, in the treatment of hematologic malignancies. Cancer Treat Rev. 2005; 31:591-602. [PubMed: 16298074]

3. Zavrski I, Kleeberg L, Kaiser M, et al. Proteasome as an emerging therapeutic target in cancer. Curr Pharm Des. 2007; 13:471-485. [PubMed: 17348844]

4. Nawrocki ST, Carew JS, Dunner K Jr, et al. Bortezomib inhibits pkr-like endoplasmic reticulum (er) kinase and induces apoptosis via er stress in human pancreatic cancer cells. Cancer Res. 2005; 65:11510-11519. [PubMed: 16357160]

5. Houghton PJ, Morton CL, Kolb EA, et al. Initial testing (stage 1) of the proteasome inhibitor bortezomib by the pediatric preclinical testing program. Pediatr Blood Cancer. 2008; 50:37-45. [PubMed: 17420992] 
6. Blaney SM, Bernstein M, Neville K, et al. Phase I study of the proteasome inhibitor bortezomib in pediatric patients with refractory solid tumors: A Children's Oncology Group study (ADVL0015). J Clin Oncol. 2004; 22:4804-4809. [PubMed: 15570082]

7. Horton TM, Pati D, Plon SE, et al. A phase 1 study of the proteasome inhibitor bortezomib in pediatric patients with refractory leukemia: A Children's Oncology Group study. Clin Cancer Res. 2007; 13:1516-1522. [PubMed: 17332297]

8. Marks P, Rifkind RA, Richon VM, et al. Histone deacetylases and cancer: Causes and therapies. Nat Rev Cancer. 2001; 1:194-202. [PubMed: 11902574]

9. Marks PA, Richon VM, Miller T, et al. Histone deacetylase inhibitors. Adv Cancer Res. 2004; 91:137-168. [PubMed: 15327890]

10. Bachmann PS, Piazza RG, Janes ME, et al. Epigenetic silencing of BIM in glucocorticoid poorresponsive pediatric acute lymphoblastic leukemia, and its reversal by histone deacetylase inhibition. Blood. 2010; 116:3013-3022. [PubMed: 20647567]

11. Leclerc GJ, Mou C, Leclerc GM, et al. Histone deacetylase inhibitors induce FGPS mRNA expression and intracellular accumulation of long-chain methotrexate polyglutamates in childhood acute lymphoblastic leukemia: Implications for combination therapy. Leukemia. 2010; 24:552562. [PubMed: 20072153]

12. Einsiedel HG, Kawan L, Eckert C, et al. Histone deacetylase inhibitors have antitumor activity in two NOD/SCID mouse models of B-cell precursor childhood acute lymphoblastic leukemia. Leukemia. 2006; 20:1435-1436. [PubMed: 16810202]

13. De los Santos M, Zambrano A, Aranda A. Combined effects of retinoic acid and histone deacetylase inhibitors on human neuroblastoma SH-SY5Y cells. Mol Cancer Ther. 2007; 6:14251432. [PubMed: 17431121]

14. Glick RD, Swendeman SL, Coffey DC, et al. Hybrid polar histone deacetylase inhibitor induces apoptosis and CD95/CD95 ligand expression in human neuroblastoma. Cancer Res. 1999; 59:4392-4399. [PubMed: 10485488]

15. Milde T, Kleber S, Korshunov A, et al. A novel human high-risk ependymoma stem cell model reveals the differentiation-inducing potential of the histone deacetylase inhibitor vorinostat. Acta Neuropathol. 2011

16. Spiller SE, Ravanpay AC, Hahn AW, et al. Suberoylanilide hydroxamic acid is effective in preclinical studies of medulloblastoma. J Neurooncol. 2006; 79:259-270. [PubMed: 16645722]

17. Fouladi M, Park JR, Stewart CF, et al. Pediatric phase I trial and pharmacokinetic study of vorinostat: A Children's Oncology Group phase I consortium report. J Clin Oncol. 2010; 28:36233629. [PubMed: 20606092]

18. Emanuele S, Lauricella M, Carlisi D, et al. SAHA induces apoptosis in hepatoma cells and synergistically interacts with the proteasome inhibitor bortezomib. Apoptosis. 2007; 12:13271338. [PubMed: 17351739]

19. Pei XY, Dai Y, Grant S. Synergistic induction of oxidative injury and apoptosis in human multiple myeloma cells by the proteasome inhibitor bortezomib and histone deacetylase inhibitors. Clin Cancer Res. 2004; 10:3839-3852. [PubMed: 15173093]

20. Yu C, Rahmani M, Conrad D, et al. The proteasome inhibitor bortezomib interacts synergistically with histone deacetylase inhibitors to induce apoptosis in Bcr/Abl+cells sensitive and resistant to STI571. Blood. 2003; 102:3765-3774. [PubMed: 12893773]

21. Heider U, von Metzler I, Kaiser M, et al. Synergistic interaction of the histone deacetylase inhibitor SAHA with the proteasome inhibitor bortezomib in mantle cell lymphoma. Eur J Haematol. 2008; 80:133-142. [PubMed: 18005386]

22. Nawrocki ST, Carew JS, Pino MS, et al. Aggresome disruption: A novel strategy to enhance bortezomib-induced apoptosis in pancreatic cancer cells. Cancer Res. 2006; 66:3773-3781. [PubMed: 16585204]

23. Drexler HC, Euler M. Synergistic apoptosis induction by proteasome and histone deacetylase inhibitors is dependent on protein synthesis. Apoptosis. 2005; 10:743-758. [PubMed: 16133866]

24. Lin Z, Bazzaro M, Wang MC, et al. Combination of proteasome and HDAC inhibitors for uterine cervical cancer treatment. Clin Cancer Res. 2009; 15:570-577. [PubMed: 19147762] 
25. Pitts TM, Morrow M, Kaufman SA, et al. Vorinostat and bortezomib exert synergistic antiproliferative and proapoptotic effects in colon cancer cell models. Mol Cancer Ther. 2009; 8:342-349. [PubMed: 19174560]

26. Fuchs O, Provaznikova D, Marinov I, et al. Antiproliferative and proapoptotic effects of proteasome inhibitors and their combination with histone deacetylase inhibitors on leukemia cells. Cardiovasc Hematol Disord Drug Targets. 2009; 9:62-77. [PubMed: 19275578]

27. Mitsiades CS, Mitsiades NS, McMullan CJ, et al. Transcriptional signature of histone deacetylase inhibition in multiple myeloma: Biological and clinical implications. Proc Natl Acad Sci U S A. 2004; 101:540-545. [PubMed: 14695887]

28. Campbell RA, Sanchez E, Steinberg J, et al. Vorinostat enhances the antimyeloma effects of melphalan and bortezomib. Eur J Haematol. 2010; 84:201-211. [PubMed: 19929977]

29. Simms-Waldrip T, Rodriguez-Gonzalez A, Lin T, et al. The aggresome pathway as a target for therapy in hematologic malignancies. Mol Genet Metab. 2008; 94:283-286. [PubMed: 18472289]

30. Hideshima T, Bradner JE, Wong J, et al. Small-molecule inhibition of proteasome and aggresome function induces synergistic antitumor activity in multiple myeloma. Proc Natl Acad Sci U S A. 2005; 102:8567-8572. [PubMed: 15937109]

31. Weber D, Badros AZ, Jagannath S, et al. Vorinostat plus bortezomib for the treatment of relapsed/ refractory multiple myeloma: Early clinical experience. Blood (ASH Annual Meeting Abstracts). 2008; 112:871.

32. Badros A, Burger AM, Philip S, et al. Phase I study of vorinostat in combination with bortezomib for relapsed and refractory multiple myeloma. Clin Cancer Res. 2009; 15:5250-5257. [PubMed: 19671864]

33. Schelman W, Kolesar J, Schell K, et al. A phase I study of vorinostat in combination with bortezomib in refractory solid tumors. J Clin Oncol, 2007 ASCO Annual Meeting Proceedings. 2007; Vol 25(Part I):3573.

34. Skolnik JM, Barrett JS, Jayaraman B, et al. Shortening the timeline of pediatric phase I trials: The rolling six design. J Clin Oncol. 2008; 26:190-195. [PubMed: 18182661]

35. Eisenhauer EA, Therasse P, Bogaerts J, et al. New response evaluation criteria in solid tumours: Revised RECIST guideline (version 1.1). Eur J Cancer. 2009; 45:228-247. [PubMed: 19097774]

36. Parise RA, Holleran JL, Beumer JH, et al. A liquid chromatography-electrospray ionization tandem mass spectrometric assay for quantitation of the histone deacetylase inhibitor, vorinostat (suberoylanilide hydroxamicacid, SAHA), and its metabolites in human serum. J Chromatogr B Analyt Technol Biomed Life Sci. 2006; 840:108-115.

37. Argyriou AA, Iconomou G, Kalofonos HP. Bortezomib-induced peripheral neuropathy in multiple myeloma: a comprehensive review of the literature. Blood. 2008; 112:1593-1599. [PubMed: 18574024]

38. Messinger Y, Gaynon P, Raetz E, et al. Phase I study of bortezomib combined with chemotherapy in children with relapsed childhood acute lymphoblastic leukemia (ALL): a report from the therapeutic advances in childhood leukemia (TACL) consortium. Pediatr Blood Cancer. 2010; 55:254-259. [PubMed: 20582937]

39. Weber D, Jagannath S, Sobecks R, et al. Combination of vorinostat plus bortezomib for the treatment of patients with multiple myeloma who have previously received bortezomib. Blood (ASH Annual Meeting Abstracts). 2008; 112:3711.

40. Ninan J, Bailey H, Kolesar J, et al. A phase I study of vorinostat in combination with bortezomib in refractory solid tumors. J Clin Oncol. 2009; 27:2531A.

41. Voorhees P, Gasparetto C, Osman K, et al. Results of a phase I study of vorinostat in combination with pegylated liposomal doxorubicin and bortezomib in patients with relapsed/refractoy multiple myeloma. Blood (ASH Annual Meeting Abstracts). 2010; 116:1955.

42. Jones MWZC, Oettel KR, Blank JH, et al. Vorinostat and bortezomib as third-line treatment in patients with advanced non-small cell lung cancer: A Wisconsin oncology network phase II study. J Clin Oncol. 2011; 29(suppl) abstr 7567.

43. Attia SMM, Okuno SH, Adkins D, et al. A phase II consortium trial of vorinostat and bortezomib for advanced soft tissue sarcomas. J Clin Oncol. 2011; 29(suppl) abstr 10075. 


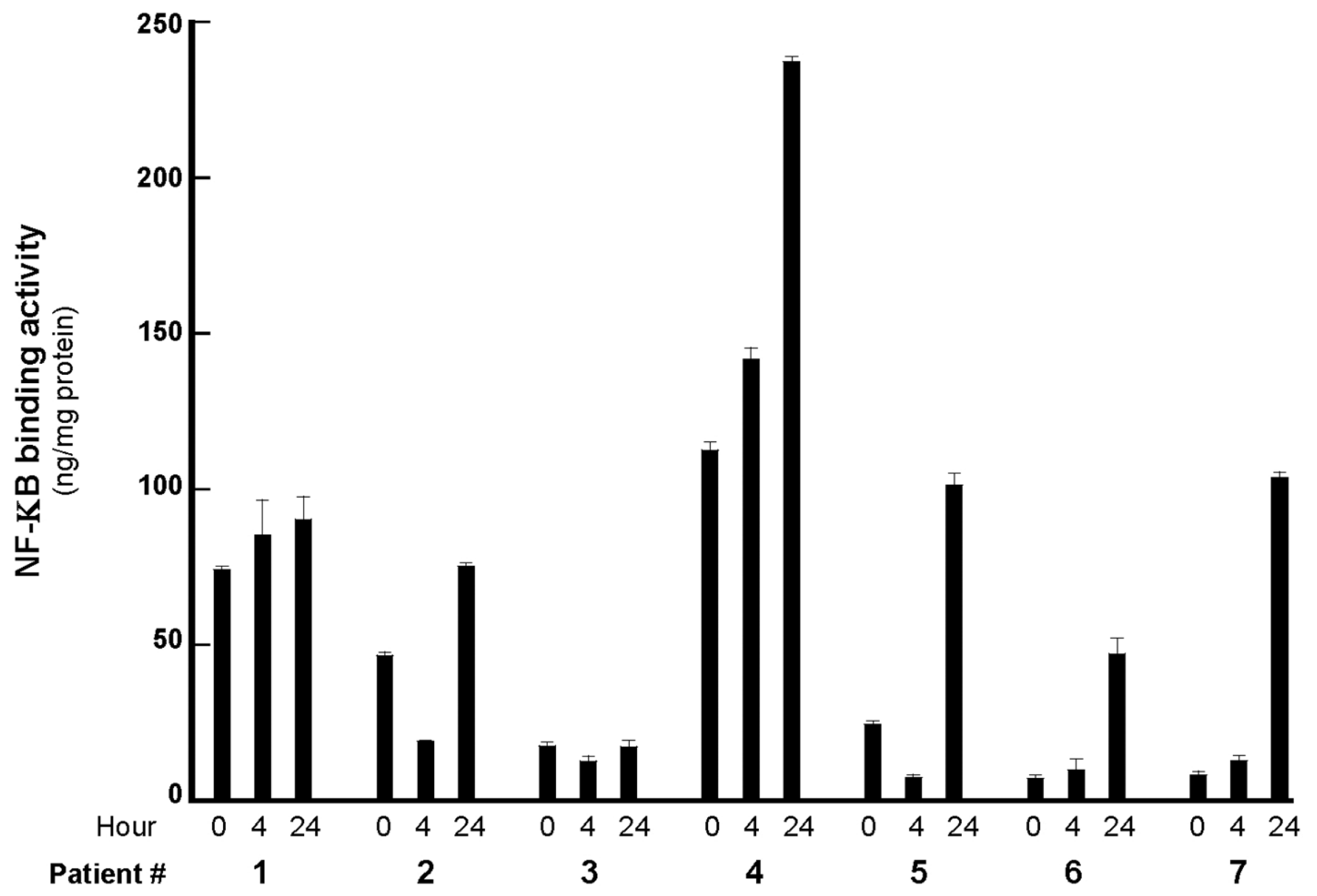

Fig 1.

NF- $\mathrm{BB}$ activity in peripheral white blood cells at 0,4 , and 24 hours after day 8 bortezomib administration. 
Table I

Patient Characteristics for Eligible Patients $(n=23)$

\begin{tabular}{|c|c|c|}
\hline \multirow{2}{*}{ Characteristic } & \multicolumn{2}{|c|}{ Patients } \\
\hline & No. & $\%$ \\
\hline \multicolumn{3}{|l|}{ Age (years) } \\
\hline Median (range) & \multicolumn{2}{|c|}{$12.6(1.1-20.1$} \\
\hline \multicolumn{3}{|l|}{ Sex } \\
\hline Male & 17 & 73.9 \\
\hline Female & 6 & 26.1 \\
\hline \multicolumn{3}{|l|}{ Diagnosis } \\
\hline \multicolumn{3}{|l|}{ CNS tumors } \\
\hline Malignant glioma & 6 & 26.0 \\
\hline Malignant peripheral nerve sheath tumor & 1 & 4.3 \\
\hline Medulloblastoma & 1 & 4.3 \\
\hline \multicolumn{3}{|l|}{ Non-CNS tumors } \\
\hline Neuroblastoma & 3 & 13.0 \\
\hline Extrarenal rhabdoid tumor & 2 & 8.7 \\
\hline Ewing sarcoma & 2 & 8.7 \\
\hline Rhabdomyosarcoma & 1 & 4.3 \\
\hline Hepatoblastoma & 1 & 4.3 \\
\hline Osteosarcoma & 1 & 4.3 \\
\hline Wilms tumor & 1 & 4.3 \\
\hline Embryonal sarcoma & 1 & 4.3 \\
\hline Carcinoma, undifferentiated & 1 & 4.3 \\
\hline Epitheliod sarcoma & 1 & 4.3 \\
\hline Retinoblastoma & 1 & 4.3 \\
\hline \multicolumn{3}{|l|}{ Prior therapy } \\
\hline \multicolumn{3}{|l|}{ Chemotherapy regimens } \\
\hline Median (range) & \multicolumn{2}{|c|}{$2(1-8)$} \\
\hline Radiation therapy (\# of patients) & \multicolumn{2}{|c|}{19} \\
\hline Bone marrow transplant (\# of patients) & \multicolumn{2}{|c|}{4} \\
\hline
\end{tabular}




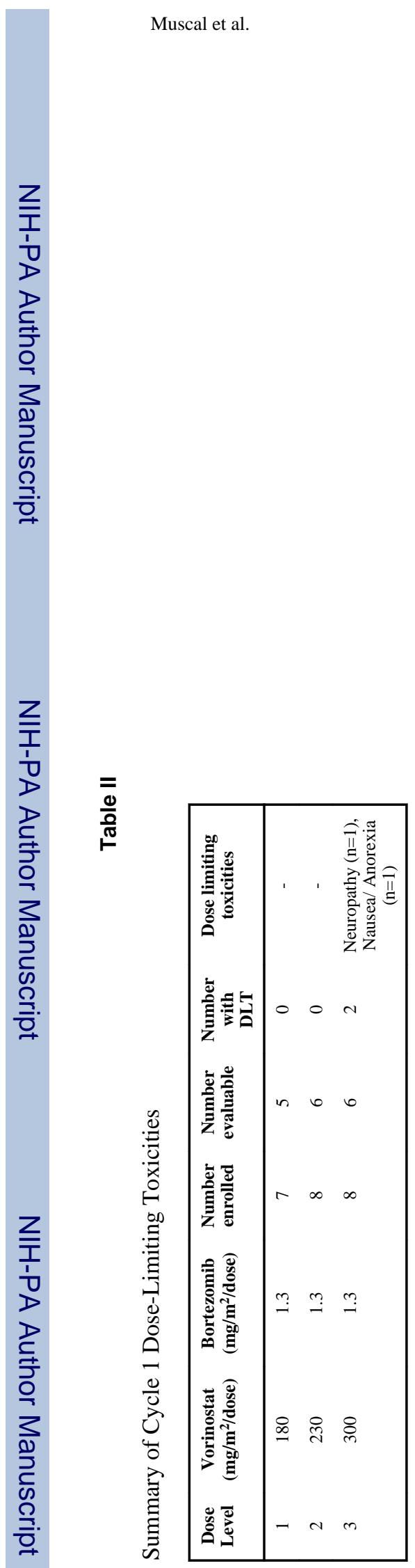

Page 12

\begin{tabular}{|c|c|c|}
\hline 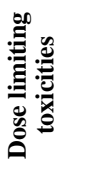 & , & 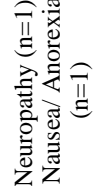 \\
\hline 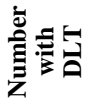 & 00 & $\sim$ \\
\hline 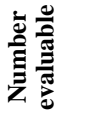 & no & 0 \\
\hline 总 & $r \infty$ & \\
\hline 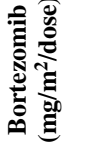 & $\stackrel{m}{-}$ & $\stackrel{?}{9}$ \\
\hline 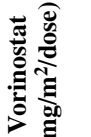 & $\stackrel{\infty}{\infty} \underset{\pi}{0}$ & \&্ল \\
\hline 㟧 & $-N$ & \\
\hline
\end{tabular}

Pediatr Blood Cancer. Author manuscript; available in PMC 2014 March 01. 


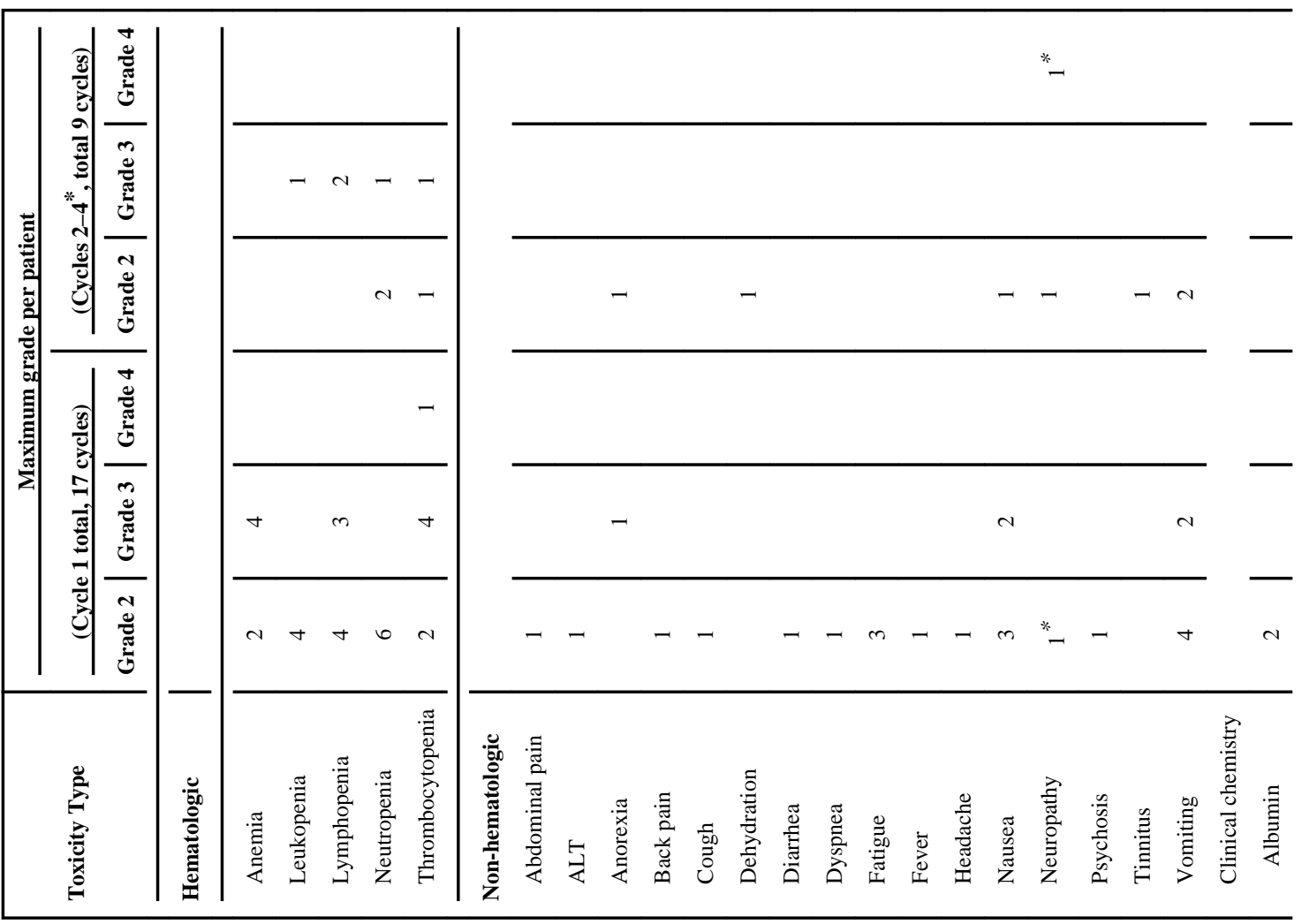

Pediatr Blood Cancer. Author manuscript; available in PMC 2014 March 01. 


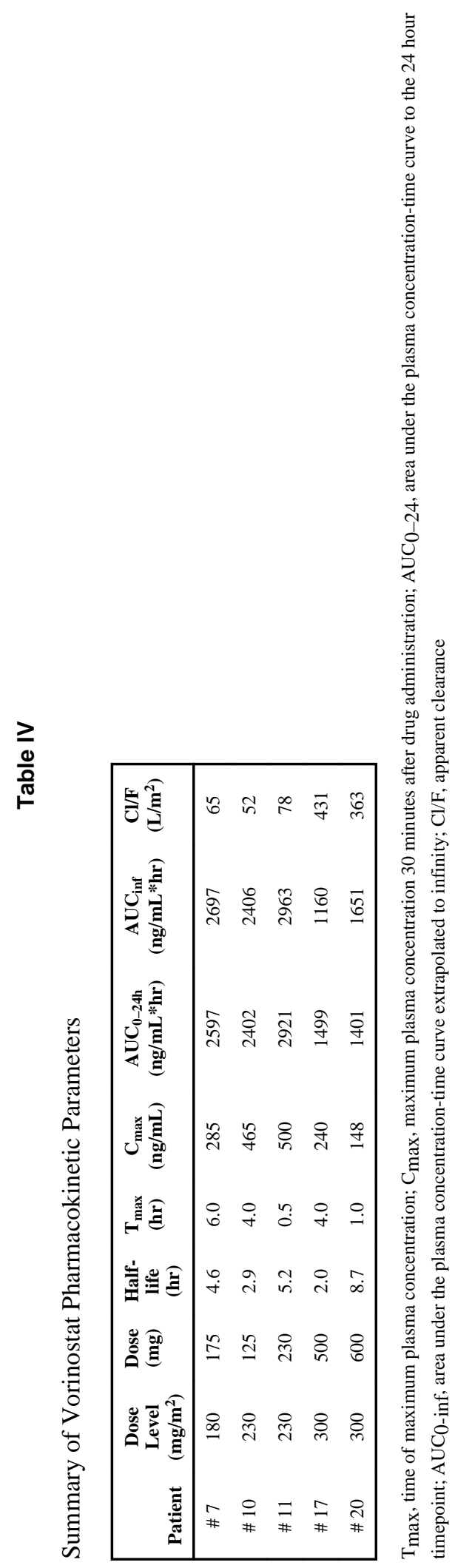

Pediatr Blood Cancer. Author manuscript; available in PMC 2014 March 01. 


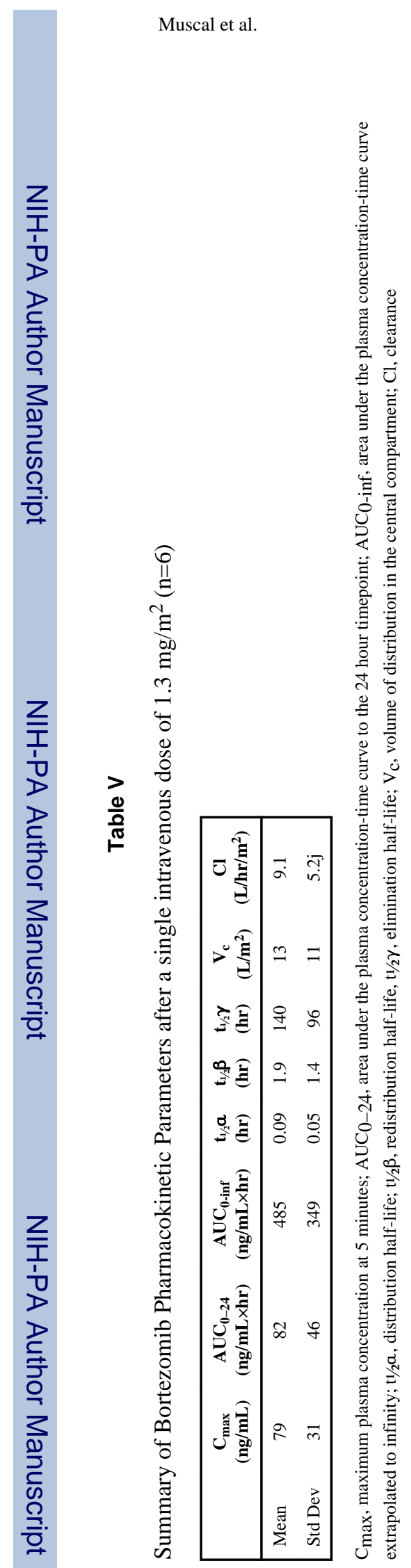

Pediatr Blood Cancer. Author manuscript; available in PMC 2014 March 01. 